\title{
An Analysis of the Factors Affecting Students’ Adjustment at a University in Zimbabwe
}

\author{
Mutambara Julia ${ }^{1} \&$ Bhebe Veni ${ }^{2}$ \\ ${ }^{1}$ Psychology department, Midlands State University, Zimbabwe \\ ${ }^{2}$ Fletcher High School, Gweru, Zimbabwe \\ Correspondence: Julia Mutambara, Psychology Department, Midlands State University, P. Bag 9055, Gweru, \\ Zimbabwe. Tel: 263-260-575 ext.277. E-mail: juliamutambara@gmail.com
}

Received: July 20, 2012

Accepted: August 16, 2012

Online Published: November 2, 2012

doi:10.5539/ies.v5n6p244

URL: http://dx.doi.org/10.5539/ies.v5n6p244

\begin{abstract}
This study provides insight into transition experiences and adjustment of students at a university in Zimbabwe. Research was based on students in the first three semesters of college. Based on prior research college adjustment was conceptualised in this study as involving personal, emotional, social and academic issues. The study was qualitative in nature and the descriptive research design using case study method was used. Structured and unstructured questionnaires were used to gather information. A sample of 115 students was selected using stratified random sampling from the faculty of social sciences. Findings from the study revealed that to a larger extent students were failing to adjust to college demands, this was compounded by the socioeconomic conditions prevailing in Zimbabwe.
\end{abstract}

Keywords: university, students, social adjustment, academic adjustment, personal and emotional adjustment

\section{Introduction}

Entering college is an important turning point for college freshmen in their early adulthood. The college life is both an opportunity and a challenge for them. If the freshmen cannot adapt to the new environment quickly, they may have difficulties in their studying and psychological developments (Wang, Chen, Zhao \& Xu, 2006). The young people of today are faced with a multi-faceted and complex world of work and highly specialized tasks and as such, spend an extended period of time in technical institutes, colleges and post-graduate centres in order to acquire specialized skills, educational experiences, and professional training (Boyd \& Bee, 2006).

Becoming a first year undergraduate student after being a final year student at school replays the top-dog phenomenon of transferring from the oldest and most powerful group of students to the youngest and least powerful group of students that occurred earlier as adolescence began (Grayson, 1989). Also, the transition into college involves movement to a larger, more impersonal school structure; interaction with peers from more diverse geographical and sometimes more diverse ethnic backgrounds; and increased focus on achievement and its assessment (Santrock, 2004). It requires the making of new friends, modifying existing relationships with family members, and adjusting to the new academic environment (Parker, Summerfeldt, Hogan, \& Majeski, 2003).

A successful adaptation to college has typically been defined by such criteria as remaining in college, enjoying psychological well-being, and performing well academically. It is well adjusted graduates who are believed to drive a strong internationally competitive economy compared with their poorly adjusted counterparts (Lapsley \& Edgerton, 2000). Entering college demands more responsibility and some students may doubt their ability to be successful at the college level which may lower their academic success and increase their stress level (Dwyer \& Cummings, 2001). Holmbek \& Wandrei (1993) suggested that some students adjust well to the college environment whereas others struggle with the transition, some leaving school entirely. However, the factors influencing first-year students' adaptation to college are complex (Wang, Chen; Zhao \& Xu 2006). While there are many challenges associated with the transition to college, it is also characterized by many positive features. It is suggested that students are more likely to feel grown-up, have more modules from which to select, have more time to spend with peers, have more opportunities to explore different lifestyles and values, enjoy greater independence from parental monitoring, and be challenged intellectually by academic work (Heaven, 2000). 
University students in Zimbabwe are learning in an environment that is characterised by poverty and insufficient resources. Zimbabwe as a country is still recovering from an economic depression that saw most universities closing due to sustainability issues during the period 2007-2009. It is estimated that 55\% (6,6 million people) are living under the food poverty line in Zimbabwe (UNICEF,2011). The average Zimbabwean is earning about US\$8.50 daily but however needs around US\$12.25 daily (Poverty Datum Line Analysis, 2012). Given such a scenario therefore were most people are living under the poverty datum line and struggling to meet everyday demands, there is need to find out how university students are adjusting to college life given the harsh ecomonic environment that is prevailing in the country.

Universities in Zimbabwe charge an average of $\$ 1000$ per year and this does not include accommodation and meals for the whole year. Kasayira, Chipandambira \& Hungwe (2007) in their study of the coping strategies used by university students in Zimbabwe noted that university students use ineffective coping strategies that predispose them to stress. With that in mind it becomes imperative to find out how students at a university in Zimbabwe are adjusting to the demands of university life. Also of significance is the fact that there is a dearth of qualitative researches that have been done on college adjustment among students in a poor resource country.

\section{Literature Review}

\subsection{Student Adjustment to College}

The term adjustment is often used as a synonym for accommodation and adaptation (Monroe 2007). It is used to emphasize the individual's struggle to survive in his or her social and physical environment. Robinson (2009) explained that the adjustment process is a way in which the Individual attempts to deal with stress, tensions, conflict and meet his or her needs. In, this process, the individual also makes efforts to maintain harmonious relationships with the environment. In adjustment, the two crucial factors are the individual and the environment.

Students who go to college come from different backgrounds and have different norms and values. The college has its own norms and values which are in line with the institution`s mission, vision and core values. Students have to fit in the college set up through adjusting their own values and behaviours to fit those of the college. The adjustment differs from one student to the other depending on the developmental stage of the individual. Dyson \& Renk (2006) support this idea when they say almost all new students go through an adjustment phase upon entry to a university with each student varied in his or her own pace of development.

Baker (1985) noted that, prior to high school freshmen have little idea about scheduling of classes. The new student has been in high school where everything is scheduled for them, study time is given to them and all they do is follow it. Freshman come to college with unspoken and unformed questions about self and the world, questions that schools and parents deliberately never allowed them to ask. They enter the university community with an enthusiasm that is often replaced by disappointment (Baker, 1985).

During college, students deal with a unique amount of stressors specifically a significant transition where students experience many firsts, including new lifestyle, friends, roommates, exposure to new cultures and alternate ways of thinking. Lapsley, \& Edgerton (2002) assert that when students can't manage these firsts, they're more likely to struggle. If students do not feel adequate or prepared to cope with the new environment of a college campus, they could easily become susceptible to depression and anxiety. Higher rates of psychological morbidity are being recorded among first year university students throughout the world (McDermott, \& Pettijohn, 2011).

\subsection{Academic Adjustment}

For most college students, the transition to the college classroom requires an adjustment of academic habits and expectations. They often must study harder to improve their study habits. Classes may be larger, instructors have differing teaching styles, assignments are lengthier and standards are higher. Students need to learn to set and balance priorities.

Rice (2009) points out that the discourses of academic disciplines in higher education can be confusing and mysterious for the freshman. The confusion can be particularly greater for students coming from cultural and language backgrounds that are different to those underpinning the dominant ideologies of higher education institutions. Monroe (2009), revealed that, academic demands increase and new social relations are established when students join higher level institutions. Students are often uncertain of their abilities to meet these demands (Robinson, 2009). Thinking independently might be a new experience for some students who are accustomed to relying on the teacher as the ultimate authority on the course subject (Titley, 1980; Robinson, 2009). 


\subsection{Social Adjustment}

Entry into college marks the first time that many students have lived away from home. In some instances, the only support system students have experienced prior to entering university was in the home environment (Rice, 2009; Soet, \& Sevig, 2006). These first-year students have to face the college experience on their own without the security of a familiar and safe support system (Al-Busaidi et al, 2011). Consequently, many first-year students report feelings of loneliness and homesickness as a result of their lack of adjustment to college (Prancer et al., 2009).

Even though first-year students may develop a number of social relationships, this does not necessarily prevent loneliness and homesickness (Curtona, 2007; Rice, 2009). It is the quality of the relationship that impacts upon loneliness. Nevertheless, in order to have a healthy adjustment, students have to embark on a period of gradual separation or detachment from home.

With regards to the transition into college, Tao, Dong, Pratt, Hunsberger, \& Pancer (2000) identified social support as the most important factor in reducing negative affects, such as depression, loneliness, and anxiety. Social adjustment is fundamental for everyone, but particularly important for undergraduate students engaged in the process of individualisation from their home. Students' social adjustment to college and/or university has been linked to students' overall adjustment (Monre, 2009). Social adjustment can be examined in terms of how well students function in their immediate environment, participation in social activities and their satisfaction with various social aspects of the university experience (Dyson, \& Rank, 2006)

The social environment of college requires adjustment on the part of new college students. The student has to fit within groups the student cares about, both inside and outside the university (Law, 2007; Cooke, Beewick, Barkham, Bradley, \& Audin, 2006). A person who identifies totally with being a student will care only about their place with other students, ignoring the values of any outside groups; someone who comes from a family that expects a university qualification will probably make friends in the university. The peer group is an especially powerful influence on new students' lives mostly because they have a need to replace family and community support systems with peer support systems (Law, 2007). Freshmen therefore have a strong need to be liked and accepted by one another and to influence and be influenced by one another. Kitzrow (2003) noted that going to college often represents the adolescent's first experience in establishing and maintaining the self outside the home.

\subsection{Personal-emotional Adjustment}

Personal-emotional adjustment refers to the psychological distress and somatic symptoms associated with the adjustment process. Heath, (1968) reported that freshmen are concerned with being part of the University. They also want to prove themselves to their peers. Proving oneself to peers often results in use of drugs and alcohol, sexual activity, and fear leading to non assertiveness and the compromising of values (Kasayira et. al., 2007).

Emotional adjustment effects achievement in an indirect way. Unstable and maladjusted students have been found to do less well in their studies in proportion to their intelligence than students who were well balanced. Failure to archive proper adjustment at university may be a precursor to psychological problems. Kitzrow (2003) noted that the number of university students struggling with mental health issues is increasing, with universities being labeled as "perfect" incubators of mental health problems.

Kasayira et. al. (2007) in their study on challenges faced by university students found that lack of finance to meet basic needs is a major stressor for university students in developing countries with other stressors including adjusting to university life peer pressure, time management and task management. Students who stay out of campus face additional stressors that included inefficient transport networks and accessing other university services. Law (2007) reported that the demands of university study made students more fatigued than nine other occupational groups, including teachers, police, and medical practitioners.

\section{Methods}

The main objective of the study was to understand students`adjustment to university in a developing country that has previously undergone an economic crisis. The research was qualitative and the researcher used the case study method. The study was based on the case of a university in Zimbabwe. The name of the university was withheld to insure privacy of the institution.

A total of 115 out of a total of 900 students in their first three semesters of university learning in the faculty of Social Science were selected through stratified random sampling to take part in the study. This represented $13 \%$ of the total population of students in the faculty and academic level. 
Questionnaires with both closed ended and open ended questions were used to collect data. The open ended questions were designed to elicit students` perceptions on some constructs related to university adjustment.115 questioners were given out to the students to complete and were then collected the following day. The students had to sign individual consent forms that were attached to the questionnaires prior to completion of questionnaires. Nine questionnaires were discarded as they were incomplete and six were not returned. Therefore a total of 100 questioners were analysed.

Constructs that were used in the questionnaire were adopted from the Student Adaptation to College Questionnaire (SACQ; Baker \& Siryk, 1984). Since the aim of the research was to dig deep into the issues concerning student adjustment the constructs that were adopted were followed up with probes to give a qualitative dimension to the data unlike in the original SACQ where data gathered is quantitative. Constructs that were selected were under the following subtopics- academic adjustment, social adjustment and personal-emotional adjustment. The reviewed literature helped the researchers to come up with the final constructs and expert analysis was used to check the appropriateness of the final instrument.

The data from the questionnaires was inputted into SPSS from which item percentages were derived and cross tabulations made. Thematic data analysis was used to anlyse data obtained through the open ended questions. The five stage model of thematic data analysis as give by Ritchie and Spencer (1994) was used.

\section{Results}

\subsection{Demographic Information}

Forty four percent of the interviewed and 56\% were male. Altogether 100 students sample responded to the questionnaire administered. Sixty eight percent of the students had completed their `A ' Levels in 2009 and 2010. Twenty percent of the students had completed in 2008, with $12 \%$ having completed before $2008.28 \%$ of the students were in level 2.1 and $32 \%$ in level 1.1.The majority of the students (40\%) were in academic level 1.2. $54 \%$ of the students were conventional students while $46 \%$ parallel (were full fee paying students).

\subsection{Academic Adjustment}

Respondents were asked how they chose the programs they are currently studying. Eighty percent of the students reported that they were studying programs of their choice while $20 \%$ of the students reported that they had not planned to do the programs they were given. The findings show that students are given a chance to do programs of their own choice but some failed to do the progarmms they wanted due to weak passes in the area of their choice.

Students were probed on the rate at which they attended lectures and $60 \%$ of the respondents claimed to have attended all lectures while $40 \%$ indicated that they had not been able to attend $100 \%$ of their lectures. Seventy percent of the students who did not attend all the lectures noted that they failed to do so because sometimes they had to go back home to look for money for everyday expenses. Twenty percent indicated that they usually missed the first few weeks after vacation since they would be working during vacation and needed time to raise more income.

Over rally $68 \%$ of the respondents expressed their satisfaction and gratitude in their studies while $32 \%$ expressed their dissatisfaction. The respondents who indicated dissatisfaction were mainly parallel students or full fee paying students. Only $6 \%$ of the students of the student respondents did not see the role of the Faculty in their settling down to their studies $.94 \%$ of the respondents strongly attributed their settling down at university to the Faculty members and structures. On time management, $74 \%$ of the respondents reported that their departments helped them come up with plans in how to manage their time. On the other hand $26 \%$ said that they did not get any help in managing their time from departmental members.

\subsection{Social Adjustment}

Fifty six percent of the respondents indicated that they were satisfied with extracurricular activities at the university while $44 \%$ of the respondents indicated that they were not satisfied with extracurricular activities that were in place. Those students who were not satisfied with the extracurricular activities that were being offered on campus noted that they could not take part in these activities since they were done on campus after lectures and by this time they would be on their way to their out of campus residences.

Seventy six percent of the respondents indicated that they were able to freely mix with students of the opposite sex, of these 50 were males and 26 were females. $24 \%$ said that they had problems mixing with the with the opposite sex, of these only 6 were males and 18 were females. It was revealed that students who had attended same sex high schools had the most difficulties mixing across sexes. 
An equal percentage of male and female respondents (64\%) indicated that they found the accommodation at the university unsettling. Most of the students who reported that they were not satisfied with accommodation were mainly from the group that had failed to get accommodation on campus and were staying in the nearby locations. This group noted that they faced electricity challenges due to load shading and also would go for some days without water due to water supply shortages in the locations they stayed in. Most students in this situation reported that they had to carry 2 litre bottles of water from campus so that at least they could cook at night and would spend a lot of time at the community borehole.

$78 \%$ of the respondents showed that they were satisfied with the friends they made on campus. Of these 50 were male and 28 were female. Only $22 \%$ indicated that they were not satisfied with the friends they made at college. Male respondents were found to be more sociable compared to their female counterparts.

Eighty eight percent of the respondents indicated a preference for voluntary academic presentation groups. They noted that group work helped them in socializing and in making friends. Students noted that being part of a group helped them to make friends with their class mates some of whom they could never had a chance to be close to.

\subsection{Personal-emotional Adjustment}

Fifty six percent of the respondents indicated that it has not been easy to take responsibility for themselves at campus. The remaining $44 \%$ reported that they did not have problems staying on their own for the first time. Most of the students who said that they were not facing any problems noted that their experiences of being in boarding schools at high school helped them adjust.

$68 \%$ of the respondents indicated that they had no problems coping with stress at college while $32 \%$ of the respondents indicated that they were facing difficulties coping with stress at college. Those who had problems with coping with stress noted that some of the stressors they encountered included financial difficulties, feeling secure in newly established sexual relationships, questioning of their religious upstanding as they came across situations that challenged their beliefs like having sex. They also noted that the freedom at campus and not having anyone asking them about the time they got home although it gave them some sense of being grown up sometimes led to confusion as they failed to have absolute boundaries on acceptable behaviour.

Half of the respondents indicated that they felt moody a lot while the other half indicated that they did not feel moody. Of the $50 \%$ who indicated that they felt moody 16 were males while 34 were females. Females therefore reported more moody feelings in comparison to their male counterparts. $80 \%$ of the respondents indicated that their personal friends helped them in their personal growth. The other $20 \%$ indicated that interpersonal relationships had no impact on their personal growth.

\section{Discussion}

The findings show that students are given a chance to do programs of their own choice but some might fail to do these due to weak passes in the area of their choice. More than half of the students indicated that financial problems were the main reasons they did not attend all their lectures. This affirms Kasaira et al (2007) findings that factors such as the emotional demands of leaving home, coping with the contrast between school and university work, working independently, exams and money worries have been noted to contribute to the mental health problems that affect university students .

Overrally $68 \%$ of the respondents expressed their satisfaction and gratitude in their studies while $32 \%$ expressed their dissatisfaction. Most of the students reported that they were helped to manage their time by staff in their departments. This is in line with a study by Baker, \& Siryk. (1984) where students listed peer support, family support, and faculty support as important determinants in their decision to remain at the university beyond their first year.

More than half of the students indicated that that they were not happy with accommodation arrangements at the university with a number of them being forced to look for alternative accommodation in the nearby high density suburbs. Kasaira et al (2007) in their study of stressors faced by university students found accommodation as one of the major problem faced by university students.

Friends that respondents had on campus were found to be the main source of support in terms of adjusting to university life. Law (2007) in his studies found out that friends that students made on campus helped them in decision making. Socialisation among university was also enhanced by the group assignments that students were given. The university has a policy that at least one of the continuous assessments that students write should be a group assignment. Students felt that group work helped them to be close to each other as they shared information 
and helped in their social adjustment. According to Chickering (1993) through group work a student is able to meet social and interpersonal demands through development of autonomy.

More than half of the respondents indicated that it has not been easy being on their own for the first time and having to take responsibility for their actions. Students still depended on their parents for their financial needs. As put forward by Chickering (1993) students` financial dependence on their parents hinders them from developing autonomy and independence.

Although the greater percentage of students did not have any problems with coping with stress at campus about a third of the students were failing to cope with stress. Gaidzanwa's 2001 study (as cited in Kasayira et. al. 2007) found that lack of finance to meet basic needs is a major stressor for university students in developing countries.

Failure to cope could have contributed to the moody feelings that students reported. More females compared to males reported feeling moody sometimes. Al-Busaidi et al (2011) reported that one in four students will experience a mental health problem whilst in university. Thus there might be need for studies that examine psychological disorders or psychopathological symptoms among students in a resource poor university. Social support was reported to be the main stress buffering tool by most of the students. Tao et al (2000) identified social support as an important factor in reducing the negative effects of university life.

\section{References}

Al-Busaidi, Z., Bhargava, K., Al-Ismaily, A., Al-Lawati, H., Al-Kindi, R., Al-Shafaee, M., \& Al-Maniri, A. (2011). Prevalence of Depressive Symptoms Among University students in Oman. Oman Medical Journal. http://dx.doi.org/10.5001/omj.2011.58

Baker, R. W., \& Siryk, B. (1984). Measuring adjustment to college. Journal of Counseling Psychology, 31, 179-189. http://dx.doi.org/10.1037/0022-0167.31.2.179

Boyd, D., \& Bee, H. (2006). Lifespan Development. 4th Ed. USA: Pearson.

Chickering, A. W. (1993). Education and Identity. San Francisco: Jossey-Bass.

Cooke, R., Beewick, B. M., Barkham, M., Bradley, M., \& Audin, K. (2006). Measuring, monitoring and managing the psychological wellbeing of first year university students. British Journal of Guidance \& Counselling, 34(4), 505-517. http://dx.doi.org/10.1080/03069880600942624

Curtona, C. E. (2007). Transition to college: Loneliness and the process of social adjustment. In L. A. Peplau \& D. Perlman (Eds.), Loneliness: A source book of current theory, research, and therapy (pp. 291-309). New York: John Wiley.

Dwyer, A. L., \& Cummings, A. L. (2001). Stress, self-efficacy, social support, and coping strategies in university students. Canadian Journal of Counseling, 35, 208-220.

Dyson, R., \& Rank, K. (2006). Freshman adaptation to university life: Depressive symptoms, stress and coping. Journal of Clinical Psychology, 62(10), 1231-1244. http://dx.doi.org/10.1002/jclp.20295

Grayson, P. A. (1989). The college psychotherapy client: An overview. New York: Guilford Press.

Heath, D. H. (1968). Growing up in College. San Francisco: Jossey-Bass.

Heaven, P. C. L. (2000). The Social Psychology of Adolescence. Basingstoke; Palgrave.

Holmbek, G. N., \& Wandrei, M. L. (1993). Individual and Relational Predictors of Adjustment in First-year $\begin{array}{lllll}\text { College Students. Journal of Counseling Psychology, 40, } & \text { 73-78. }\end{array}$ http://dx.doi.org/10.1037/0022-0167.40.1.73

Kasayira, J. M., Kapandambira, K. S., \& Hungwe, C. (2007). Stressors faced by University students and their coping strategies: A Case of Midlands State University in Zimbabwe. 37th ASEE/IEEE Frontiers in Education Conference, F1A: 22-28.

Kitzrow, M. A. (2003). The mental health needs of today's college student: Challenges and recommendations. NASPA Journal, 41, 167-181.

Lapsley, D. K., \& Edgerton, J. (2002). Separation-Individuation, Adult Attachment Style, and College Adjustment. Journal of Counselling and Development, 80, 484-492. http://dx.doi.org/10.1002/j.1556-6678.2002.tb00215.x

Law, D. W. (2007). Exhaustion in university students and the effect of coursework involvement. Journal of American College Health, 55, 239-245. http://dx.doi.org/10.3200/JACH.55.4.239-245 
McDermott, L. A., \& Pettijohn, T. F. (2011). The influence of clothing fashion and race on the perceived socioeconomic status and person perception of college students. Poster presented at the 23rd Annual Association for Psychological Science Convention, Washington, D.C.

Monroe, P. (2009). International encyclopaedia of education. (Ed.) New Delhi: Cosmo Publications.

Parker, J. D. A., Summerfeldt, L. J., Hogan, M. J., \& Majeski, S. A. (2004). Emotional intelliegence and academic success: examining the transition from high school to university. Personality and Individual Differences, 36, 163-172. http://dx.doi.org/10.1016/S0191-8869(03)00076-X

Poverty Datum Line Analysis. (Monday, 19 March 2012). Retrieved from http://www.zbc.co.zw/news-categories/business/17699-poverty-datum-line-analysis.html

Prancer, S. M., Hunsberger, B., Pratt, M. W., \& Alisat, S. (2009). Cognitive complexity of Expectations and adjustment to university in the first year. Journal of Adolescent Research, 15, 38-57. http://dx.doi.org/10.1177/0743558400151003

Rice, K. G. (2009). Separation-individuation and adjustment to college, A longitudinal study. Journal of Counseling Psychology, 39, 203-213. http://dx.doi.org/10.1037/0022-0167.39.2.203

Ritchie, J., \& Spencer, L. (1994). Qualitative data analysis for applied policy research. London, Sage.

Robinson, J. (2009). “International students and American university culture: Adjustment Issues”, Paper presented at the meeting of the Washington Area Teachers of English to Speakers of Other Languages Annual Convention, Arlington, VA.

Santrock, J. W. (2004). Child Development. 10th Ed. New York: McGraw-Hill.

Soet, J., \& Sevig, T. (2006). Mental health issues facing a diverse sample of college students: Results from the College Student Mental Health Survey. NASPA Journal, 43, 410-431.

Tao, S., Dong, Q., Pratt, M. W., Hunsberger, B., \& Pancer, S. M. (2000). Social support: Relations to coping and adjustment during the transition to university in the People's Republic of China. Journal of Adolescent Research, 15, 123-144. http://dx.doi.org/10.1177/0743558400151007

Titley, B. S. (1980). Initial Choice College Major: Are the "Undecided" Undecided? Journal of College Student Personnel, 21, 293-298

UNICEF. (2011). UNICEF Says 6.6 million Zimbabweans Living Below Food Poverty Line. Retrieved from http://www.voanews.com/Zimbabwe/news

Wang, A., Chen L., Zhao, B., \& Xu, Y. (2006). First-year Students' Psychological and Behavior Adaptation to College:The Role of Coping Strategies and Social Support. US-China Education Review, 3, 27-36. 